\title{
Estudo da durabilidade de argamassas alternativas contendo resíduos
}

\section{(Durability study of alternative mortars containing wastes)}

\author{
J. Farias Filho ${ }^{1}$, R. R. Menezes ${ }^{2}$, H. S. Ferreira ${ }^{2}$, L. N. L. Santana ${ }^{1}$, G. A. Neves ${ }^{1}$, H. C. Ferreira ${ }^{1}$ \\ ${ }^{I}$ Departamento de Engenharia de Materiais, Universidade Federal de Campina Grande, \\ Campus I, Campina Grande, PB \\ ${ }^{2}$ Departamento de Engenharia de Materiais, Universidade Federal da Paraíba, \\ Cidade Universitária, João Pessoa, PB 58059-900 \\ gelmires@dema.ufcg.edu.br,heber@dema.ufcg.edu.br, lisiane@dema.ufcg.edu.br
}

\begin{abstract}
Resumo
O interesse pela preservação dos recursos naturais e a busca pelo desenvolvimento sustentável tem despertado interesse de um grande número de pesquisadores visando obter materiais de construção não convencionais. Dentre essas possibilidades, destacamse os resíduos produzidos pela construção civil e pela indústria de beneficiamento de granito, em virtude do volume gerado e os impactos ambientais do seu descarte inadequado. Este trabalho tem como objetivo estudar a durabilidade das argamassas alternativas incorporadas com resíduos de construção civil e da serragem do granito. Para quantificar a durabilidade dos materiais estudados, foram realizados ensaios de envelhecimento natural e ensaios de envelhecimento acelerado através de ciclos de molhagem e secagem, visando simular condições de utilização e avaliar sua degradação. Nos estudos da durabilidade foram utilizados traços de argamassas para alvenaria de elevação, com percentagens de substituição, em peso, da cal por resíduo de 30\% e 50\%. Os resultados para o envelhecimento natural evidenciaram o comprometimento da durabilidade do material após 60 dias com redução no comportamento mecânico, sendo os melhores resultados para os corpos-de-prova com 30\% e 50\% de resíduo de construção. No envelhecimento acelerado, para os tratamentos adotados, os resultados evidenciaram a ação da formação de silicoaluminatos de cálcio e potássio que favoreceram um aumento do comportamento mecânico e, além disso, não foi observado o comprometimento da sua durabilidade. Palavras-chave: resíduos de granitos, resíduos de construção civil, reciclagem, durabilidade.
\end{abstract}

\begin{abstract}
The preservation of natural resources and search for sustainable development are increase in interest by the researchers with the aim to obtain knowledge of non conventional materials. Among these possibilities stand out the recycling of residues from civil construction and from granite industry, which are producers of large amount of residues and causing great environmental impacts. The aim of this work is to study the durability of the alternative mortar incorporated with residues from civil construction and from granite industry. To quantify the durability of the studied materials, it was made test of natural and accelerated weathering through wetting and drying cycles. The materials were submitted to conditions that simulated their use to evaluate their degradation. In the studies of durability of the mortar elevation, percentages of substitutions of lime by recycling residue were used. The amount changed from $30 \%$ to $50 \%$. The natural weathering cause a compromise in the durability of the material after 60 days with a decrease in the mechanical behavior and the best results occur to the sample with $30 \%$ and $50 \%$ of residue. In the accelerated weathering, the results show indicate the formation of calcium and potassium aluminosilicates that can give an increase in the mechanical behavior, however, it was not observed a compromise in the material durability.

Keywords: granite waste, civil construction waste, recycling, durability, resistance to compression.
\end{abstract}

\section{INTRODUÇÃO}

No Brasil as indústrias da construção civil e de mineração principalmente do beneficiamento de rochas ornamentais geram grandes volumes de resíduos sólidos. Centenas de toneladas destes resíduos, por ano, são responsáveis pela poluição e contaminação do meio ambiente. Este quadro é agravado ainda mais pelos indicativos de crescimento da produção, despertando a preocupação de ambientalistas e da comunidade em geral, em vista de um cenário ainda mais perigoso e danoso ao meio ambiente e à saúde da população. Nos últimos anos pesquisas sobre a reciclagem desses resíduos para uso em construção civil tem se intensificado, destacando os trabalhos para produção de argamassas de alvenarias, principalmente na substituição do agregado miúdo [1-5]. Embora haja vários estudos envolvendo a reciclagem de resíduos para fins de construção civil, muitas pesquisas ainda precisam ser desenvolvidas de modo a se obter informações sobre o comportamento e as propriedades destes materiais ao longo do tempo. Este entendimento possibilitará estabelecer a real relação entre reciclagem, desempenho tecnológico e ecologia, contribuindo na busca por desenvolvimento sustentável, amparando-o em fundamentos científicos [6]. 
Os materiais utilizados na construção civil sofrem ação de inúmeros agentes que provocam o seu envelhecimento $[6,7]$. O envelhecimento pode ser genericamente definido como qualquer processo de degradação produzido pela interação entre o material e o ambiente, alterando sua estrutura e suas propriedades dimensionais, mecânicas, elétricas, químicas ou térmicas. Esse processo de constantes mudanças nas condições a que os materiais são submetidos (umidade, temperatura, etc.) faz com que se desconheça a velocidade de deterioração, favorecendo o surgimento de patologias prematuras e a necessidade de recuperações antecipadas [8, 9]. Estes fatores são, via de regra, os responsáveis pelo desconhecimento e/ou dificuldade em se conhecer ou dominar o comportamento de envelhecimento e durabilidade dos materiais de construção, particularmente os mais recentes, como os resíduos.

No estudo da durabilidade dos materiais vários parâmetros podem ser avaliados, principalmente, as propriedades mecânicas através da resistência à compressão simples. A dificuldade na avaliação da durabilidade dos materiais alternativos, produzidos com resíduos reciclados, está associada à complexidade dos constituintes desses resíduos, que depende diretamente do ambiente onde foram originados, da fase ou estágio da sua geração, tipo ou tratamento a que o material que lhe deu origem foi processado, como também sua interação com os agentes ou mecanismos de degradação ambiental aos quais serão submetidos para avaliação dos indicadores da durabilidade $[10,11]$. A durabilidade é um dos fatores mais importantes para o conhecimento dos novos materiais em desenvolvimento. Para que se haja confiabilidade nas características tecnológicas de um novo material e indicação deste como uma possibilidade técnica, a ser disponibilizada no mercado, é fundamental o conhecimento de suas condições de uso e de sua vida útil [10-13]. As pesquisas sobre durabilidade de materiais alternativos são incipientes, podendo se destacar os resíduos da construção civil na forma de agregados para uso em concretos, argamassas e compósitos com fibras vegetais, etc. Nestes estudos foram avaliados diferentes tratamentos e condições de exposição. Entretanto, devemos salientar que não existe um modelo ou metodologia padrão para realização de estudo da durabilidade. Os resultados dos trabalhos desenvolvidos até o momento vêm buscando desenvolver procedimentos de forma a apontar diretrizes para os estudos de análise de durabilidade [10, 14-16].

Este trabalho tem como objetivo estudar a durabilidade de argamassas convencionais e alternativas incorporadas com resíduos de construção civil e da serragem de granito, utilizando os processos de envelhecimento natural e acelerado através de secagem e molhagem.

\section{MATERIAIS E MÉTODOS}

Foram utilizados os seguintes materiais: resíduo da serragem de granito, identificado por Gr (cedido pela empresa Fuji S.A. Mármore e Granito, Campina Grande, PB); três resíduos da construção e demolição, coletados em obras de edificações em Campina Grande, PB e identificados por RC-01, RC-02 e RC-03; cal calcítica [18] (Carbomil, Fortaleza, CE); cimento Portland composto com filler, CPII-F [19], fabricado pela Cia. de Cimento Nassau, Recife, PE e areia (Município de Barra de Santana, PB), com diâmetro máximo de 1,2 mm e módulo de finura de $0,36 \%$ (determinado segundo normalização da ABNT [20]). O resíduo de granito é o resíduo mais fino, apresentando uma distribuição multimodal com concentração de partículas em torno de 2, 8, 20 e $40 \mu \mathrm{m}$ [17]. Os resíduos, RC-01, RC02, RC-03 e Gr, apresentaram $\mathrm{D}_{10}, \mathrm{D}_{50}$ e $\mathrm{D}_{90}$ de 3,30 e 80 $\mu \mathrm{m}$, de $2,3,15$ e $65 \mu \mathrm{m}$, de 2,23 e $60 \mu \mathrm{m}$ e de 1,6 e 30 $\mu \mathrm{m}$, respectivamente. As seguintes fases mineralógicas estão presentes nos resíduos: mica, quartzo, feldspato, carbonato de cálcio e óxido de ferro [17]. Os resíduos de construção RC-01, RC-02 e RC-03 foram coletados segundo a norma da ABNT NBR [21]. O resíduo de granito, Gr, foi originário dos teares e apresenta-se em forma de polpa de coloração cinza, de fácil desagregação após o processo de secagem. Os resíduos de construções foram triturados através de um britador de mandíbulas e posteriormente, moídos em moinho de galga e passado na peneira ABNT $200(0,074 \mathrm{~mm})$. As argamassas convencional e alternativas utilizadas para estudo da durabilidade foram preparadas no traço 1:4:28 (cimento, cal, areia), em massa, e fator água/ aglomerante determinados de acordo com a norma da ABNT NBR [22]. Nas argamassas alternativas foram incorporados os teores de resíduos de construção e resíduo de granito na proporção de $30 \%$ e $50 \%$ de substituição, em massa, a cal. Após pesagem dos materiais em balança de precisão, de acordo com a dosagem estabelecida, estes foram colocados em misturador do tipo betoneira de eixo excêntrico com movimento planetário, permanecendo em movimento até a homogeneização do material. Após a moldagem, os corposde-prova foram mantidos nos respectivos moldes por um período de $24 \mathrm{~h}$. Foram curados em imersão por 28 dias e, em seguida, determinanda a sua resístência à compressão simples (RCS), segundo a norma da ABNT NBR [22]. Os corpos-de-prova foram expostos às condições climáticas ambientais por 60, 90, 120, 180 dias e, após cada período, foi avaliada a RCS segundo a norma da ABNT NBR [22].

No ensaio de durabilidade acelerada os corpos-de-prova foram submetidos, após o período de cura em imersão por 28 dias, ao processo de envelhecimento acelerado, com ciclos alternados de molhagem e secagem. Os corpos-de-prova foram avaliados após 20, 30, 45, 60 e 90 ciclos. A definição do ciclo foi baseada em resultados anteriores $[6,10]$. O ciclo de envelhecimento acelerado foi composto por imersão dos corpos em água por $3 \mathrm{~h}$, exposição do corpo ao ar por 30 min, secagem do corpo em estufa com ventilação forçada por $20 \mathrm{~h}$, exposição do corpo ao ar por $30 \mathrm{~min}$. Foram duas as temperaturas de secagem, $60{ }^{\circ} \mathrm{C} \pm 5{ }^{\circ} \mathrm{C}$ e $45^{\circ} \mathrm{C} \pm 5{ }^{\circ} \mathrm{C}$, denominando-se, assim, os dois ciclos de envelhecimento $\mathrm{C} 1$ e $\mathrm{C} 2$, respectivamente.

O controle do processo de envelhecimento natural e acelerado foi efetuado por difração de raios $X$ pela determinação qualitativa das fases e por evolução do 
comportamento mecânico na forma de resistência à compressão simples. Na difração de raios $X$ foi usado um difratômetro de raios X Shimadzu D 6000 com radiação Cuk $\alpha$ com varredura de $2^{\circ}$ a $45^{\circ}$ com velocidade de $1,3^{\circ} /$ min. $\mathrm{O}$ ensaio de resistência à compressão simples foi efetuado em corpo-de-prova cilíndrico de $5 \mathrm{~cm}$ x $10 \mathrm{~cm}$ [22].

\section{RESULTADOS E DISCUSSÃO}

Nas Figs. 1 e 2 estão apresentados os difratogramas de raios $\mathrm{X}$ dos corpos-de-prova convencionais e alternativos incorporados com $30 \%$ e $50 \%$ de resíduos e curados por períodos de 28 dias e 180 dias.

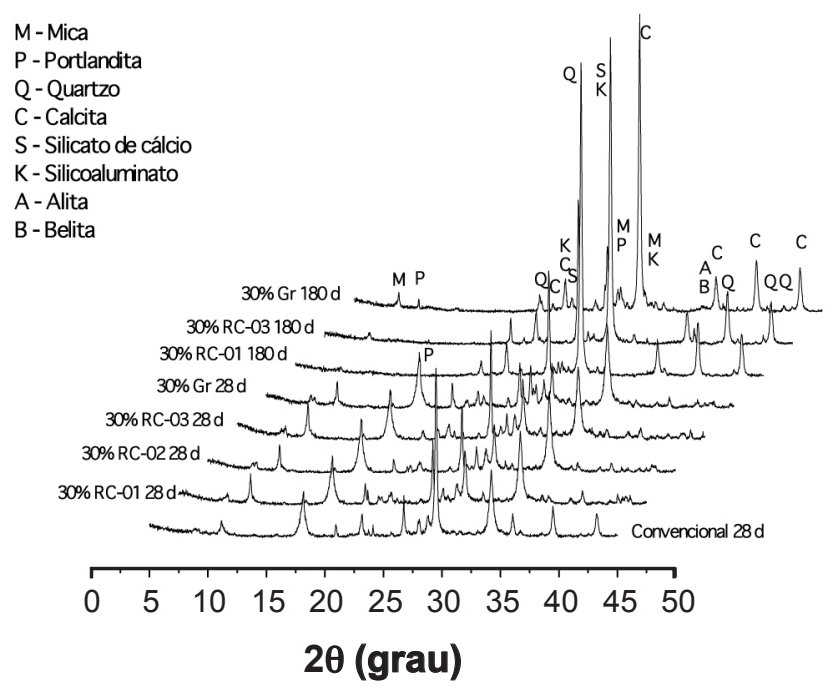

Figura 1: Difratogramas de raios $\mathrm{X}$ dos corpos-de-prova convencionais e alternativos incorporados com 30\% de resíduo, curados por períodos de 28 e 180 dias.

[Figure 1: X-ray diffraction patterns of conventional and alternative samples with incorporation of waste, 30\%, cured for 28 and 180 days.]

Com 30\% de resíduo verificou-se que os corpos-deprova apresentaram as seguintes fases mineralógicas: quartzo $\left(\mathrm{SiO}_{2}\right)$, caracterizado pela distância interplanar de 3,34 A, portlandita $\mathrm{Ca}(\mathrm{OH})_{2}$, caracterizada pelas distâncias interplanares de 2,62 $\AA, 5,60 \AA$ e 3,23 $\AA$, calcita $\left(\mathrm{CaCO}_{3}\right)$ caracterizada pelas distâncias interplanares 3,03 $\AA$ e 2,13 , em menor quantidade silicato de cálcio $\left(\mathrm{C}_{2} \mathrm{Si}\right)$ caracterizado por 3,36 e 3,19 , silicoaluminatos de cálcio e potássico $\left(\mathrm{Na}_{2} .8 \mathrm{KO} .6 \mathrm{CaO} \cdot 2 \mathrm{Al}_{3} \cdot 8 \mathrm{Si}_{4} \cdot 2 \mathrm{O}_{16}\right)$, caracterizados por 3,24 $\AA$ e $2,29 \AA$ e mica moscovita, caracterizada por $10,04 \AA$. Observou-se, também, nos difratogramas dos corpos-deprova com 28 dias de cura a portlandita. Analisando-se a evolução do envelhecimento, há uma diminuição da fase portlandita e surgimento da calcita como fase decorrente das reações ocorridas da cal com $\mathrm{CO}_{2}$ do ar ambiente, favorecendo a carbonatação. Mudanças de fases semelhantes foram observadas [10, 24].

Os corpos-de-prova incorporados com $50 \%$ de resíduo apresentaram as seguintes fases mineralógicas: quartzo,

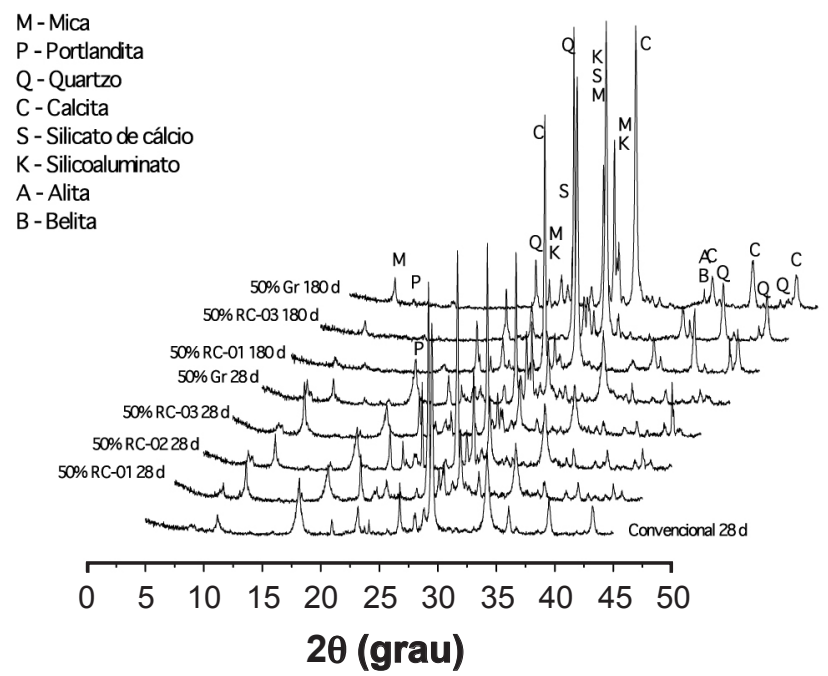

Figura 2: Difratogramas de raios $\mathrm{X}$ dos corpos-de-prova convencionais e alternativos incorporados com 50\% de resíduo, curados por períodos de 28 e 180 dias.

[Figure 2: X-ray diffraction patterns of conventional and alternative samples with incorporation of waste, 50\%, cured for 28 and 180 days.]

portlandita, calcita e, em menor quantidade, silicato de cálcio, silicoaluminatos de cálcio e potássico e mica moscovita. Observou-se, também, nos difratogramas dos corpos-de-prova por período de 28 dias a portlandita, tendo estes picos praticamente desaparecido com a evolução do tempo de envelhecimento. Verificou-se, também, com a evolução do tempo, uma forte presença da calcita, em decorrência das reações ocorridas entre a cal e o $\mathrm{CO}_{2}$ do ar ambiente que favorece a carbonatação. Mudanças de fases semelhantes foram observadas [7].

Na Fig. 3 estão apresentadas às curvas de resistência à

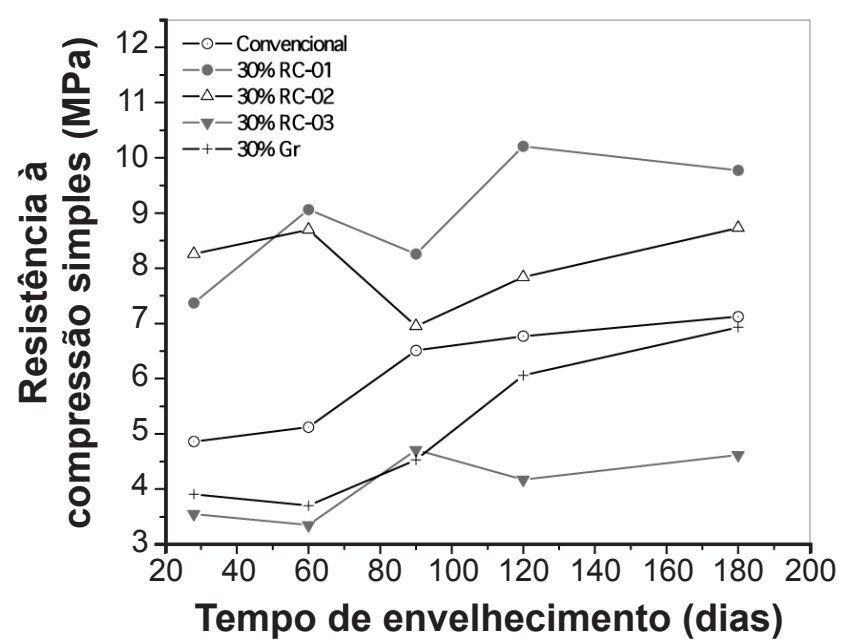

Figura 3: Resistência à compressão simples dos corpos-de-prova convencionais e alternativos com $30 \%$ de resíduo, submetido à durabilidade natural por períodos de 28 dias, 60 dias, 90 dias, 120 dias e 180 dias.

[Figure 3: Compressive strength conventional and alternative samples with incorporation of waste, $30 \%$, subjected to natural durability for periods 28 days , 60 days, 90 days 120 days and 180 days.] 
compressão simples dos corpos-de-prova moldados com $30 \%$ de resíduo, submetidos ao envelhecimento natural, por períodos de $28,60,90,120$ e 180 dias.

Para os corpos-de-prova incorporados com 30\% de RC-01 o tempo de envelhecimento foi completado até um valor máximo de 10,21 $\mathrm{MPa}$ aos 120 dias, sendo o aumento da RCS na ordem de $38,53 \%$, o que corresponde a 2,84 MPa, em relação a RCS obtida aos 28 dias de cura. Para a argamassa com $30 \%$ de RC-02, o aumento da RCS atingiu o valor máximo de $8,73 \mathrm{MPa}$, aos 180 dias, resultando em um crescimento da ordem de $5,69 \%$, o que corresponde a $0,47 \mathrm{MPa}$, em relação a RCS obtida aos 28 dias. Para os corpos-de-prova com $30 \%$ de RC-03 o envelhecimento não foi completado, até um valor máximo de 4,71 MPa, aos 90 dias, resultando um crescimento da ordem de $38,53 \%$, o que corresponde a 2,84 MPa, em relação a RCS obtido aos 28 dias. Para os corpos-de-prova com $30 \%$ de $\mathrm{Gr}$, o processo de envelhecimento continuou até um valor máximo de 6,93 $\mathrm{MPa}$, aos 180 dias, resultando em um crescimento na ordem de $77,23 \%$, o que corresponde a $3,02 \mathrm{MPa}$, em relação a RCS obtida aos 28 dias. Comparando-se este resultado com aqueles obtidos dos corpos-de-prova convencionais aos 28 dias e 180 dias, observou-se para os corpos-de-prova RC-01 um crescimento de $110,05 \%$ e $63,58 \%$, o que corresponde a 5,37 MPa e 3,09 $\mathrm{MPa}$, respectivamente. Para o RC-02 observou-se um crescimento de $18,45 \%$ e $22,61 \%$, o que corresponde a 1,36 MPa e 1,61 $\mathrm{MPa}$, respectivamente. Para RC-03 observou-se uma queda de $3,08 \%$ e $33,84 \%$, o que corresponde a $0,15 \mathrm{MPa}$ e 2,41 MPa, respectivamente. Comparando-se com os resultados obtidos anteriormente [12] verificou-se que o comportamento é semelhante.

Em relação ao tempo de envelhecimento verificou-se que os valores de RCS dos corpos-de-prova RC-01, RC-02 começaram a decrescer, atingindo no final do período, uma queda de $4,99 \%$ e $1,91 \%$ respectivamente, afetando, assim, a durabilidade do material. Este decréscimo, de acordo com a Fig. 1, pode ser atribuído à diminuição da portlandita e a forte presença da calcita resultante da reação entre a cal e $\mathrm{CO}_{2}$ do ar ambiente que favorece a carbonatação, quando as argamassas estão submetidas a esse tempo de envelhecimento. Estes resultados confirmam estudos realizados [10,24] sobre a influência da carbonatação no comportamento mecânico, conseqüentemente, na durabilidade dos corpos-de-prova, quando submetidos ao envelhecimento natural.

Na Fig. 4 são apresentadas as curvas de resistência à compressão dos corpos-de-prova incorporados com $50 \%$ de resíduo, submetidos ao envelhecimento natural por períodos de $28,60,90,120$ e 180 dias.

Os valores da RCS dos corpos-de-prova incorporados com 50\% de RC-01 começaram a decrescer a partir dos 60 dias. No final do período a perda de RCS foi de 33,07\%. Para os corpos-de-prova incorporados com $50 \%$ RC-02 os valores de RCS apresentaram comportamento semelhante ao RC-01 a partir do 120 dias, com a continuação do processo e até o final do período analisado o valor de RCS foi reduzida em $10,42 \%$. Os corpos-de-prova incorporados com $50 \%$ de RC-03 começaram a mostrar redução no comportamento

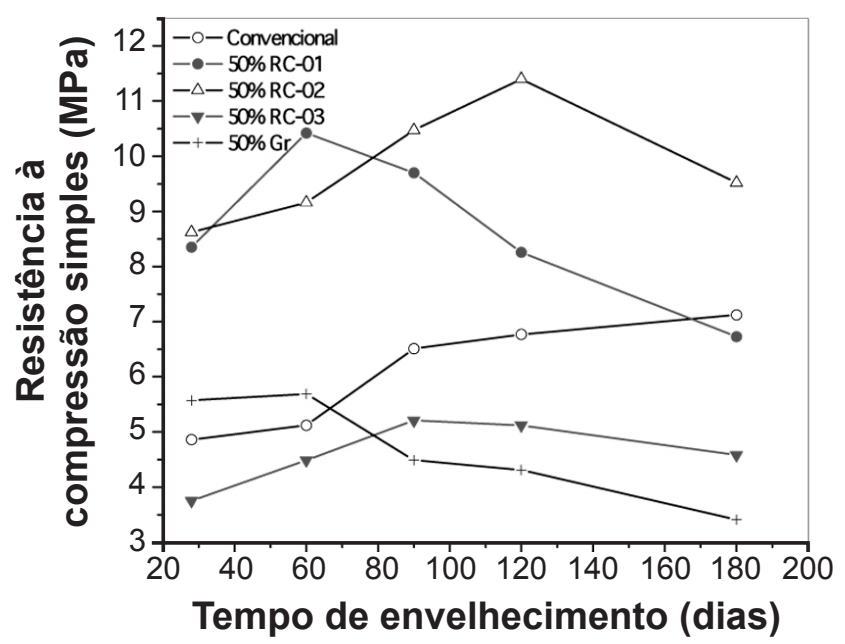

Figura 4: Resistência à compressão simples dos corpos-de-prova convencionais e alternativos com incorporação de $50 \%$ de resíduo, submetido ao envelhecimento natural por períodos de $28,60,90$, 120 e 180 dias.

[Figure 4: Compressive strength conventional and alternative samples with incorporation of waste, 50\%, subjected to natural durability for periods $28,60,90120$ and 180 days.]

da RCS a partir do 90 dias e ao final essa perda foi de $12,09 \%$. Os resultados da RCS para os corpos-de-prova incorporados com $50 \%$ de $\mathrm{Gr}$ começaram a decrescer a partir dos 60 dias. No final do período a perda da RCS foi de $40,07 \%$. Comparando-se os resultados dos corpos-de-prova incorporados com $50 \%$ de resíduos com os convencionais aos 28 dias e 180 dias, verifica-se um crescimento de $71,81 \%$ e uma redução de $5,47 \%$, o que corresponde a 3,49 $\mathrm{MPa}$ e $0,39 \mathrm{MPa}$, respectivamente para os corposde-prova incorporados com RC-01. Para os corpos-deprova incorporados com $50 \%$ de RC-02, observou-se um crescimento de $77,36 \%$ e $33,70 \%$, o que corresponde a 3,76 $\mathrm{MPa}$ e 2,40 MPa respectivamente. Para os corpos-de-prova incorporados com $50 \%$ RC-03, observou-se uma redução de $22,83 \%$ e $35,67 \%$, o que corresponde a $1,11 \mathrm{MPa}$ e 2,54 MPa, respectivamente. Para os corpos-de-prova incorporados com $50 \%$ de Gr, verificou-se um aumento de $14,60 \%$ e uma redução na ordem de $52,10 \%$, o que corresponde a 0,71 $\mathrm{MPa}$ e 3,71 $\mathrm{MPa}$, respectivamente. Em relação ao tempo de envelhecimento verifica-se que os valores de RCS dos corpos-de-prova RC-01, RC-02 começaram a decrescer após os 60 dias e 120 dias, atingindo no final do período uma queda de $35,41 \%$ e $29,32 \%$, respectivamente, caracterizando que a durabilidade do material foi afetada. Comparando-se esses resultados com aqueles obtidos por Farias Filho [6] e Oliveira [10], verifica-se que os valores apresentaram comportamento semelhante. Para os corpos-de-prova com os resíduos RC-03 e Gr, decréscimos nos valores de RCS foram observados a partir dos 90 dias e 60 dias, atingindo ao final do período de cura uma redução de $12,09 \%$ e 40,07\% respectivamente. Este decréscimo na RCS pode ser atribuído ao desaparecimento da fase portlandita (Fig. 3) que ocorreu com evolução do tempo de envelhecimento e o aparecimento da calcita em decorrência das reações ocorridas entre a 
cal e o $\mathrm{CO}_{2}$ do ar ambiente que favorece a carbonatação. Embora a carbonatação por si só não constitua uma forma de degradação da argamassa nem de sua deterioração, impedirá a reação pozolânica, reduzindo a durabilidade do material. Estes resultados confirmam estudos sobre a influência da carbonatação no comportamento mecânico quando submetido ao ensaio de durabilidade $[25,26]$.

Nas Figs. 5 e 6 são apresentados os difratogramas de raios $\mathrm{X}$ dos corpos-de-prova submetidos ao envelhecimento acelerado, através de ciclos alternativos de molhagem e secagem, curados por período por 28 dias e 180 dias.



Figura 5: Difratogramas de raios $\mathrm{X}$ dos corpos-de-prova convencionais e alternativos incorporados com 30\% de resíduo, curado por período de 28 dias e a 90 ciclos de molhagem e secagem. [Figure 5: X-ray diffraction patterns of conventional and alternative samples with incorporation of waste, 30\%, and cured by period of 28 days and 90 cycles of wetting and drying.]

Nos corpos-de-prova convencionais e alternativos aos 28 dias e após 90 ciclos observam-se seguintes fases: quartzo, portlandita, calcita e, em menor quantidade, silicato de cálcio, silicoaluminatos de cálcio e potássico e mica moscovita. Nos difratogramas dos corpos-de-prova com 28 dias de cura observa-se a presença de picos de média intensidade da portlandita, sendo esses picos reduzidos a sua intensidade com o envelhecimento provocado pelos ciclos de molhagem e secagem a que foram submetidos. Verifica-se que inversamente à diminuição da portlandita, há formação de nova fase com destaque para presença da calcita decorrente das reações ocorridas entre $\mathrm{Ca}(\mathrm{OH})_{2}$ e $\mathrm{CO}_{2}$ do ar ambiente, favorecendo a carbonatação. Comparandose estes resultados com os obtidos para o mesmo percentual de utilização de resíduos quando submetidos ao envelhecimento natural, observou-se uma maior presença dos silicoaluminatos de cálcio e alumínio nos corpos-deprova submetidos ao envelhecimento acelerado.

No processo de envelhecimento acelerado através de ciclos de molhagem e secagem, após 90 ciclos, para os corpos-de-prova com $30 \%$ de resíduo, verificou-se a presença da portlandita e calcita, atribuídas à aceleração da



Figura 6: Difratogramas de raios $\mathrm{X}$ dos corpos-de-prova convencionais e alternativos incorporados com $50 \%$ de resíduo, curado por período de 28 dias e 90 ciclos.

[Figure 6: X-ray diffraction patterns of conventional and alternative samples with incorporation of waste, 50\%, cured by period of 28 days and 90 cycles of wetting and drying.]

atividade pozolânica favorecida pela ação da temperatura a que foram submetidos no processo de secagem. Devido a menor ação da carbonatação observou-se maior presença dos silicoaluminatos de cálcio e potássio.

Nos corpos-de-prova convencional, aos 28 dias, a portlandita e a calcita destacam-se como fase de forte presença. Observa-se para os corpos-de-prova convencional e alternativos a presença de quartzo, a portlandita, calcita, em menor quantidade silicato de cálcio, silicoaluminatos de cálcio e potássico e mica moscovita. À medida que o processo de envelhecimento acontece, verifica-se que há evolução de maior destaque dos silicatos presentes e a presença da calcita em decorrência das reações ocorridas entre $\mathrm{Ca}(\mathrm{OH})_{2}$ e $\mathrm{CO}_{2}$ do ar. Estes resultados confirmam os reportados [27].

Na Fig. 7 estão apresentadas as RCS dos corpos-deprova com $30 \%$ de resíduo, submetidos ao envelhecimento acelerado, utilizando-se a técnica do ciclo de molhagem e secagem, com estufa regulada $65^{\circ} \mathrm{C} \pm 5^{\circ} \mathrm{C}$ - tratamento $\mathrm{C} 1$.

Os corpos-de-prova incorporados com $30 \%$ dos resíduos da construção civil e resíduos de granito apresentaram comportamento mecânico inferior ao da argamassa convencional em todas as idades avaliadas, embora os resultados obtidos para as argamassas alternativas tenham demonstrado que os corpos-de-prova não apresentaram nenhuma evidência do envelhecimento do material. Isto pode ser observado nas curvas por meio da tendência de crescimento do início do envelhecimento até o final do processo aos 90 ciclos. Este comportamento observado para a RCS pode ser atribuído à presença da portlandita e da calcita (Fig. 5) que favorecem a aceleração da reação pozolânica e a presença dos silicoaluminatos de cálcio e potássio, em virtude da temperatura a que foram submetidos no processo de envelhecimento. Neste percentual de 


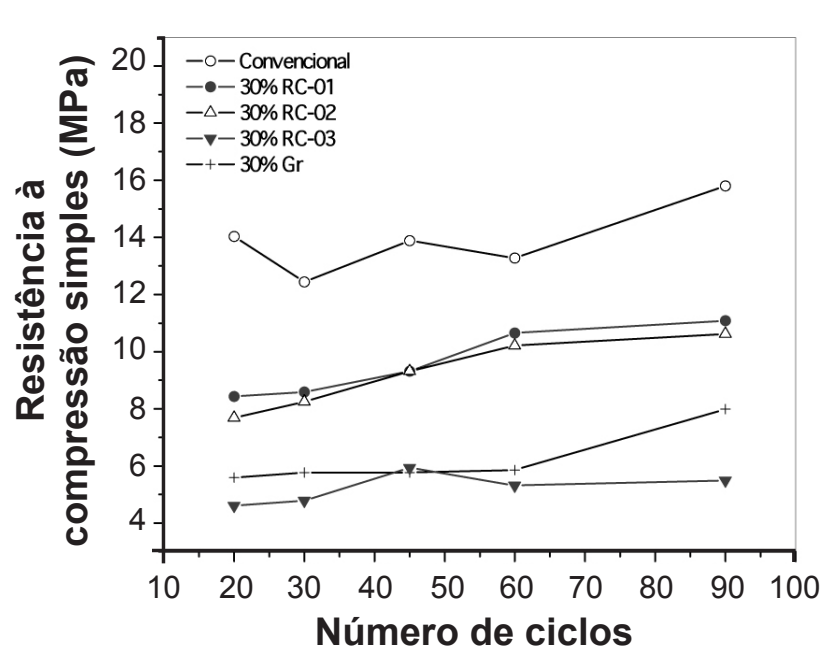

Figura 7: Resistência à compressão simples dos corpos-de-prova convencionais e alternativos com $30 \%$ de resíduo, submetidas ao envelhecimento acelerado - $\mathrm{C} 1$.

[Figure 7: Compressive strength conventional and alternative samples with incorporation of waste, $30 \%$, subjected to accelerated durability test - C1.]

utilização de resíduos e nestas condições a que os corposde-prova foram submetidos ao processo de envelhecimento acelerado não ficou evidenciado o comprometimento da durabilidade do material.

Na Fig. 8 estão apresentadas as resistências à compressão dos corpos-de-prova convencional com $50 \%$ dos resíduos de construção e de granito submetidos ao envelhecimento acelerado, tratamento $\mathrm{C} 1$. Analisando-se os resultados para os corpos-de-prova com $50 \%$ do resíduo de construção RC-01, verificou-se que este apresentou inicialmente RCS superior ao convencional, mantendo esse comportamento durante praticamente todo período de avaliação. Apenas aos

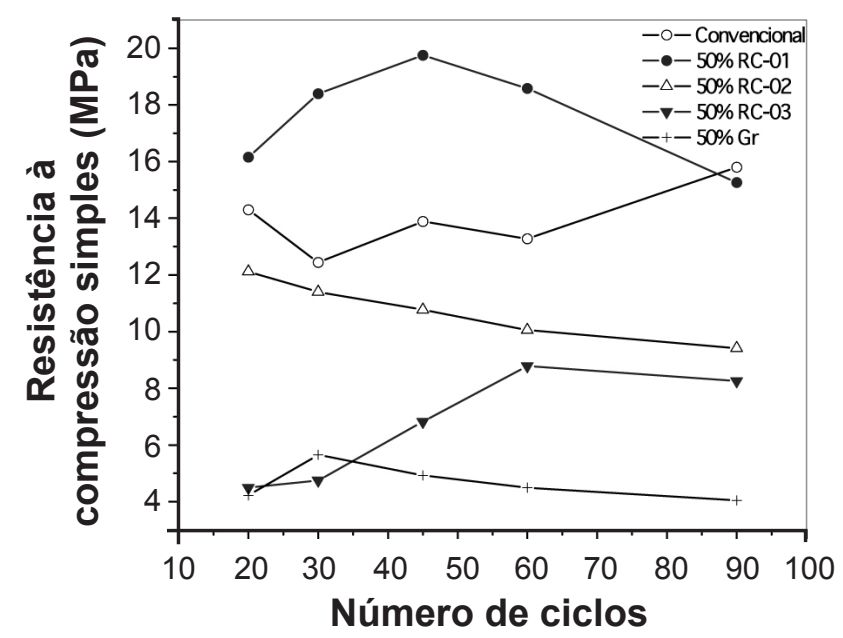

Figura 8: Resistência à compressão simples dos corpos-de-prova convencionais e alternativos com 50\% de resíduo, submetidas ao envelhecimento acelerado - $\mathrm{C} 1$.

[Figure 8: Compressive strength conventional and alternative samples with incorporation of waste, 50\%, subjected to accelerated durability test - C1.]
90 ciclos houve uma redução na RCS de $0,54 \mathrm{MPa}$, o que representa cerca de 3,41\%. Em relação ao resíduo RC-02, observou-se que o processo de envelhecimento iniciou-se após o período de cura de 20 ciclos.

Para os corpos-de-prova com o resíduo RC-03 o envelhecimento não ocorreu visto que a RCS continuou evoluindo até final do período de avaliação. Os resultados da RCS durante todo o processo mantiveram-se inferiores aos obtidos para os convencionais sugerindo que o material não foi afetado pelo processo de envelhecimento acelerado a que foi submetido. Para o resíduo Gr o envelhecimento iniciou em 30 ciclos, quando o comportamento da RCS começa a apresentar valores inferiores ao máximo obtido de 5,69 MPa. Ao final do período de observação a redução na resistência à compressão simples foi de 1,61 MPa representando cerca de $28,29 \%$. Em relação aos convencionais verificou-se que a RCS dos corpos-de-prova incorporados com resíduos foram inferiores. O comportamento observado para a RCS pode ser atribuído à presença da portlandita, observado na difração de raios X (Fig. 6), que pode ter contribuído para a aceleração da reação pozolânica, combinado com a presença dos silicoaluminatos de cálcio e potássio. Isto pode ser atribuído às condições de envelhecimento acelerado a que os corpos-de-prova foram submetidos.

Na Fig. 9 estão apresentadas as resistências à compressão dos corpos-de-prova convencionais e alternativos com $30 \%$ de resíduos de construção e resíduo de granito, submetidos ao envelhecimento acelerado, utilizando-se a técnica de ciclo de molhagem e secagem, com estufa regulada a $45{ }^{\circ} \mathrm{C}$ $\pm 5^{\circ} \mathrm{C}$, tratamento $\mathrm{C} 2$.

Para os corpos-de-prova incorporados com resíduos de construção, com $30 \%$ de RC-01 o envelhecimento não foi comprometido, obtendo-se um valor máximo de 11,24 $\mathrm{MPa}$ aos 90 ciclos, sendo o aumento da RCS da ordem de $24,19 \%$, o que corresponde a 2,19 MPa, em relação a RCS



Figura 9: Resistência à compressão simples dos corpos-de-prova convencionais e alternativos com $30 \%$ de resíduo, submetidas ao envelhecimento acelerado - $\mathrm{C} 2$.

[Figure 9: Compressive strength conventional and alternative samples with incorporation of waste, $30 \%$, subjected to accelerated durability test - C2.] 
obtida aos 20 ciclos. Para os corpos-de-prova com $30 \%$ de RC-02, o aumento da RCS atingiu o valor máximo de 20,06 $\mathrm{MPa}$, aos 90 ciclos, resultando um crescimento na ordem de $63,35 \%$, o que corresponde a $8,37 \mathrm{MPa}$, em relação a RCS obtida aos 20 ciclos de envelhecimento. Para os corpos-deprova com $30 \%$ de RC-03, não foi afetada a durabilidade até um valor máximo de 13,76 MPa, aos 90 ciclos, resultando em um crescimento na ordem de $52,04 \%$, o que corresponde a 4,71 MPa em relação a RCS obtida aos 20 ciclos. Para os corpos-de-prova com $30 \%$ de resíduo de granito (Gr), a RCS continuou a evoluir até um valor máximo de 9,94 $\mathrm{MPa}$, aos 90 ciclos, resultando um crescimento na ordem de $27,27 \%$, representando 2,13 $\mathrm{MPa}$, em relação a RCS obtida aos 20 ciclos. Comparando-se estes resultados com aqueles obtidos dos corpos-de-prova convencionais aos 20 e 90 ciclos, observa-se para os corpos-de-prova RC-02 uma redução de $14,39 \%$ e um crescimento de $26,96 \%$, o que corresponde a 2,02 MPa e 4,26 MPa respectivamente. Os demais corpos-deprova apresentaram RCS inferiores ao convencional em todas as idades, embora tenha sido caracterizado que a durabilidade do material não foi comprometida. Ficou caracterizado que a presença da portlandita e dos silicoaluminatos em todos os percentuais estudados após 90 ciclos de molhagem e secagem, observados nos difratogramas de raios X (Fig. 5) contribuíram para aceleração da reação pozolânica em decorrência da temperatura a que os corpos-de-prova foram submetidos no processo de secagem e, como conseqüência, alteração na durabilidade dos corpos-de-prova.

Na Fig. 10 estão apresentadas as resistências à compressão dos corpos-de-prova convencionais e alternativos com 50\% de resíduos de construção e de granito, submetidos ao envelhecimento acelerado, utilizando-se a técnica do ciclo de molhagem e secagem, tratamento $\mathrm{C} 2$. Observa-se que para os corpos-de-prova incorporados com resíduos de construção com $50 \%$ de RC-01, a cura não foi concluída até um valor máximo de 21,81 MPa aos 30 ciclos, sendo o aumento da RCS na ordem de $97,55 \%$, o que corresponde a $10,77 \mathrm{MPa}$, em relação a RCS obtida aos 20 ciclos. Para os corpos-deprova com $50 \%$ de RC-02, o aumento da RCS atingiu o valor máximo de $18,55 \mathrm{MPa}$, aos 30 ciclos, resultando em um crescimento na ordem de $63,27 \%$, o que corresponde a 7,19 MPa, em relação a RCS obtida aos 20 ciclos. Com $50 \%$ de RC-03, após a cura aos 20 ciclos, começou-se a apresentar redução na resistência à compressão simples. Ao final do período de envelhecimento acelerado em que foram analisados verificou-se uma redução na RCS de $2,73 \mathrm{MPa}$, o que corresponde à cerca de $20,28 \%$, em relação à obtida aos 20 ciclos.

Para os corpos-de-prova com $50 \%$ de resíduo de granito (Gr), verificou-se um aumento da RCS até um valor máximo de 12,22 MPa aos 30 ciclos, resultando em um crescimento na ordem de 19,88\%, o que corresponde a 2,08 MPa, em relação a RCS obtida aos 20 ciclos. Comparando-se este resultado com aqueles obtidos dos corpos-de-prova convencionais aos 20 ciclos e 90 ciclos, observou-se que os corposde-prova RC-01 e RC-02 apresentaram comportamento mecânico (RCS) superior em todos os ciclos analisados. Os



Figura 10: Resistência à compressão simples dos corpos-de-prova convencionais e alternativos com 50\% de resíduo, submetidas ao envelhecimento acelerado - $\mathrm{C} 2$.

[Figure 10: Compressive strength conventional and alternative samples with incorporation of waste, 50\%, subjected to accelerated durability test - C2.]

demais corpos-de-prova apresentaram RCS inferiores ao convencional em todas as idades estudadas. Esta redução no comportamento mecânico pode ser atribuída às condições de envelhecimento acelerado a que os corpos-de-prova foram submetidos. Ficou caracterizado que a presença da portlandita, observada nos difratogramas de raios X para os corpos-de-prova submetidos ao envelhecimento acelerado (Fig. 6), contribuiu para a aceleração da reação pozolânica em decorrência da temperatura a que os corpos-de-prova foram submetidos no processo de secagem e, como conseqüência, alteração na durabilidade dos corpos-de-prova.

Analisando conjuntamente os resultados, observou-se que os corpos-de-prova com $40 \%$ RC- 01 e $50 \%$ de RC-02 apresentaram melhor comportamento mecânico em relação ao envelhecimento acelerado. Verificou-se que os valores da RCS da maioria dos corpos-de-prova incorporados com resíduos começaram a apresentar comprometimento na durabilidade após os 30 ciclos de molhagem e secagem. Isto pode ser atribuído à presença da portlandita e dos silicoaluminatos de cálcio e potássio observados nos difratogramas de raios $\mathrm{X}$ para os corpos-de-prova submetidos ao envelhecimento acelerado (Figs. 5 e 6), contribuindo para aceleração da reação pozolânica em decorrência da temperatura a que os corpos-de-prova foram submetidos no processo de secagem e, como conseqüência, alteração na durabilidade dos corposde-prova. Alterações no comportamento mecânico e na durabilidade dos materiais convencionais e alternativos, através de envelhecimento acelerado utilizando ciclos de molhagem e secagem, foram observados [10], quando se estudou o comportamento desta propriedade mecânica para blocos de vedação confeccionados com resíduos da construção civil. Comparando-se os tratamentos utilizados para envelhecimento natural e envelhecimento acelerado através dos difratogramas de raios X, Figs. 1 e 2 e Figs. 5 e 6 , observou-se que nos corpos-de-prova submetidos 
ao envelhecimento natural, após 180 dias de tratamento, não apresentou a portlandita como fase constituinte $\mathrm{e}$ apresentou a calcita com fase predominante, sugerindo que no processo de envelhecimento natural os corpos-de-prova foram afetados pela carbonatação, que impediu a conclusão da reação pozolânica. Para os corpos-de-prova submetidos ao envelhecimento acelerado, após 90 ciclos, em todas as percentagens de incorporação de resíduos utilizados, observou-se a presença da portlandita. Isto sugere que o processo de envelhecimento acelerado através da técnica do ciclo de molhagem e secagem, nas condições adotadas neste trabalho, possibilitou que a reação pozolânica tenha sido realizada, visto que o método utilizado inibiu que a ação da carbonatação tivesse maior influência sobre o comportamento mecânico, o que foi causado pela formação dos silicoaluminatos de cálcio e potássio. Comparando-se os tratamentos utilizados para envelhecimento natural (Figs. 3 e 4) e acelerados (Figs. 7-10), observou-se que os corpos-deprova submetidos ao envelhecimento acelerado (tratamento C1 e C2), apresentaram comportamentos mecânicos superiores ao envelhecimento natural. Isto confirma os resultados obtidos na difração de raios X com a formação dos silicoaluminatos de cálcio. A carbonatação pode ter sido o fator que mais contribuiu para degradação do material, visto que essa reação favorece a formação de uma "capa" protetora nas proximidades das bordas dos corpos-de-prova impedindo a penetração do ar e, consequentemente, do $\mathrm{CO}_{2}$, não permitindo a continuidade do processo de carbonatação. O hidróxido de cálcio restante reagiu com os silicatos formando silicoaluminatos de cálcio e potássio em menor quantidade, quando comparada como os ciclos de molhagem e secagem onde as temperaturas mais elevadas favoreciam as reações pozolânicas, obtendo melhora na resistência à compressão simples.

\section{CONCLUSÕES}

Os valores de RCS começaram a diminuir após 60 dias de envelhecimento natural para a maioria dos corpos de prova incorporados com resíduos de construção e granito, sendo a carbonatação das argamassas responsável diretamente pela alteração no comportamento mecânico dos corpos-de-prova, sendo que os melhores resultados para argamassas incorporadas com 30\% RC-01 apresentou melhor comportamento mecânico em relação ao tempo de envelhecimento. Os corpos-de-prova submetidos ao envelhecimento acelerado, após 90 ciclos de molhagem e secagem, apresentam as fases quartzo, portlandita, calcita e, em maior quantidade, silicoaluminato de cálcio e potássio, em relação ao comportamento mecânico. Os valores de RCS começaram a diminuir após 60 dias de envelhecimento natural para a maioria dos corpos de prova incorporados com resíduos de construção e granito, sendo que a carbonatação das argamassas contribuiu diretamente para alteração no comportamento mecânico dos corpos-de-prova. Há um processo de envelhecimento nos corpos contendo resíduo, sendo observado, principalmente, nos corpos-de-prova expostos ao meio ambiente, enquanto que os corpos-de-prova envelhecidos artificialmente em laboratório apresentaram uma melhor resistência ao processo de envelhecimento (através do processo de secagem e molhagem), evidenciando os problemas existentes na avaliação da durabilidade de novos materiais através de ensaios acelerados.

\section{REFERÊNCIAS}

[1] B. A. Ajdukiewicz, T. A. Kliszczewicz, Proc. Int. Conf. Concrete for Environment Enhancement and Protection Concrete in the Service of Mankind, Dundee (1996) 115.

[2] S. C. Ângulo, Caracterização de agregrados de resíduos de construção e demolição reciclados e a influência de suas características no comportamento mecânico de concretos, Tese Dr., Universidade de S. Paulo, SP (2005) 167p.

[3] S. C. Ângulo, V. M. John, Rev. Ci. Tecnol. Mater. Constr. Civil 1, 9 (2004) 22.

[4] L. Z. D'Agostino, L. Soares, Geoci. 22, 1 (2003) 65.

[5] J. Farias Filho, G. A. Neves, H. C. Ferreira, J. W. B. Nascimento, L. F. L. Lucena, Proc. Int. Conf. Energy, Environment and Disaster (INCEED), Charlote, EUA (2005) 552.

[6] J. Farias Filho, Estudo da durabilidade de argamassas alternativas produzidas de resíduos de construção e granito, Tese Dr., Universidade Federal de Campina Grande, PB (2007) 224p.

[7] G. Le Saout, E. Lécolier, A. Rivereau, H.Zanni, Cement Concrete Res. 36 (2006) 71.

[8] S. M. Levy, Contribuição ao estudo da durabilidade de concretos, produzidos com resíduos de concreto e alvenaria. Tese Dr., Universidade de S. Paulo, SP (2001) 194p.

[9] D. O. Nik, Cement Concrete Composites 27 (2005) 315. [10] D. F. Oliveira, Contribuição ao estudo da durabilidade de blocos de concreto produzidos com a utilização de entulho da construção civil, Tese Dr., Universidade Federal de Campina Grande, PB (2004) 218p.

[11] Z. Owsaik, Cement Concrete Res. 28 (2004) 7.

[12] H. Reinhardt, M. Stegmaier, Cement Concrete Res. 33 (2005) 1.

[13] K. K.Sideris, A. E. Savva, J. Papayianni, Cement Concrete Composites 36 (2006) 1047.

[14] A. C. Silva, Estudo da durabilidade de compósitos reforçados com fibra de celulose, Diss. Mestrado, Universidade de S. Paulo, SP (2002) 128p.

[15] A. Yagüe, S. Valls, E. Vázquez, F. Albareda, Cement Concrete Res. 35 (2005) 1064.

[16] K. Wang, H. Hsieh, Cement Concrete Res. 31, 13 (2004) 5.

[17] R. R. Menezes, J. Farias Filho, H. S. Ferreira, G. A. Neves, H. C. Ferreira, Cerâmica 55, 335 (2009) 263.

[18] Associação Brasileira de Normas Técnicas, NBR 7175, Cal hidratada para argamassa, Rio de Janeiro, RJ (1992).

[19] Associação Brasileira de Normas Técnicas, NBR 11578, Cimento Portland composto, Rio de Janeiro, RJ (1992).

[20] Associação Brasileira de Normas Técnica, NBR 7200, Revestimento de parede e teto com argamassas - Materiais, 
preparo, aplicações e manutenção-procedimento, Rio de Janeiro, RJ (1982).

[21] Associação Brasileira de Normas Técnicas, NBR 10007, Amostragem de resíduos sólidos, Rio de Janeiro, RJ (2004).

[22] Associação Brasileira de Normas Técnicas, NBR 7215, Cimento Portland - Determinação da resistência a compressão simples, Rio de Janeiro, RJ (1996).

[23] A. Katz, Cement Concrete Res. 33 ( 2003) 703.

[24] P. Nischer, Proc. RILEM Seminar, Hannover, Alemanha
(1984) 231.

[25] J. Barra, Estúdio de la durabilidad del hormigón de árido reciclado em su aplicación com hormigón armado, Tese Dr., Escola Técnica Superior d'Engenyers de Camins, Canals i Ports, Universidade Politécnica de Catalunya, Barcelona, Espanha (1996) 223p.

[26] M. Hamada, Proc. Fifth Int. Symp. Chem. Cement, Tokyo, Japão, II-3 (1969) 343.

[27] C. Ulsen, Proc. Int. Cong. Appl. Mineralogy, S. Paulo, SP (2004) 63.

(Rec. 23/08/2010, Ac. 21/09/2010) 